
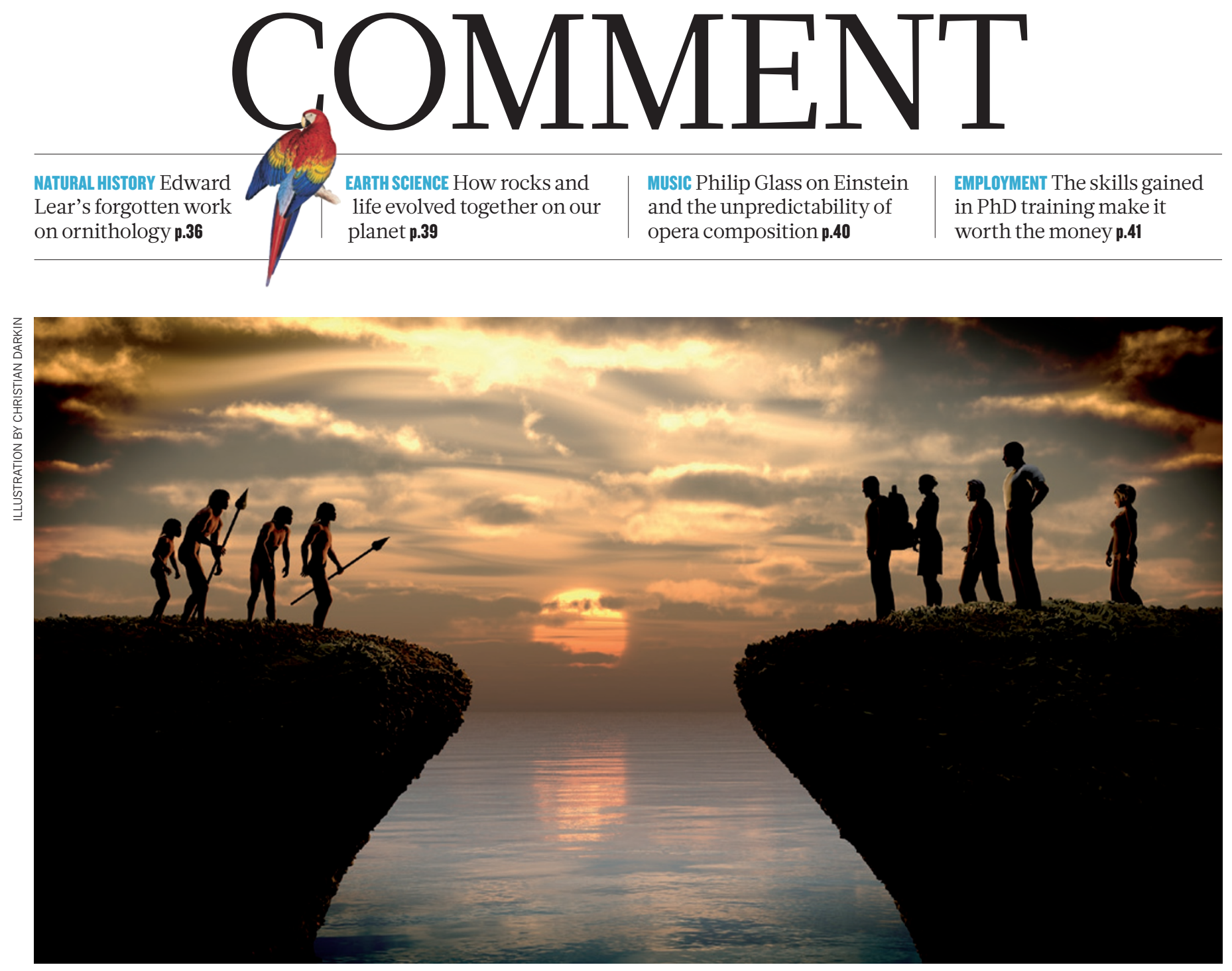

\title{
What makes a modern human
}

We probably all carry genes from archaic species such as Neanderthals. Chris Stringer explains why the DNA we have in common is more important than any differences.

I n many ways, what makes a modern human is obvious. Compared with our evolutionary forebears, Homo sapiens is characterized by a lightly built skeleton and several novel skull features. But attempts to distinguish the traits of modern humans from those of our ancestors can be fraught with problems.

Decades ago, a colleague and I got into difficulties over an attempt to define (or, as I prefer, diagnose) modern humans using the skeletal morphology that is preserved in fossils ${ }^{1}$. Our attempt was well-intentioned: we were trying to set up strict criteria, based on cranial measurements, to test whether controversial fossils from Omo Kibish in Ethiopia were within the range of human skeletal variation today - anatomically modern humans.

Our results suggested that one skull was modern, whereas the other was

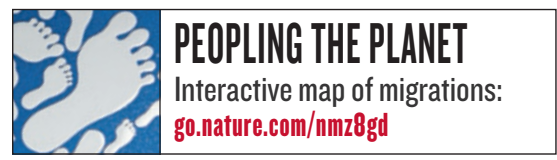

non-modern (or, in palaeontological terms, archaic). What I did not foresee was that some researchers who were not impressed with our test would reverse it, applying it back onto the skeletal range of all modern humans to claim that our diagnosis wrongly excluded some skulls of recent populations from being modern ${ }^{2}$. This, they suggested, implied that some people today were more 'modern' than others. Although I disputed what I considered to be a misuse of our test, I had to recognize the dangers inherent in this prescriptive $>$ 
$\checkmark$ approach to modern human variation.

Today, scientists are facing a similar situation. In 2010, DNA evidence showed that after modern humans left Africa about 60,000 years ago, they bred for a short period of time with archaic humans - and, as a result, some populations today have more archaic genes than others ${ }^{3}$. These genes might be expressed in the phenotype, and may require a rethink about how and when regional variation developed in $H$. sapiens. Those with alternative agendas may also try to use these new data to rank modern human populations in terms of supposedly different degrees of modernity. Already I'm reading blogs that speculate about whether some groups are less 'modern' than others, and I fear that such discussions endanger the considerable progress promised by palaeogenetic research.

So to highlight these issues and steer the debate in a positive direction, I would like to assert that the term modern humans, by definition, equally describes all humans living today. Some of us may have more DNA from archaic populations than others, but the great majority of our genes, morphology and behaviour derives from our common African heritage. And what unites us should take precedence over that which distinguishes us from each other.

\section{OUT OF AFRICA}

For the past 25 years, there has been a fierce debate about whether our species evolved from distinct ancestors who were spread across the Old World (multiregional evolution) or whether, as I have advocated, we evolved recently in only one area - Africa (recent African origin). I have argued that the physical traits of modern humans can be divided into two sets of features, which have

originated through different mechanisms and over different time scales ${ }^{3}$. The first set includes features shared by all living humans — such as a high and rounded skull, small brow ridge and a bony chin on the lower jaw $^{3}$ - that make it clear a skull belongs to H. sapiens, and not an ancient form. These traits had evolved in Africa by 100,000 years ago, and were exported from there in an exodus that began about 60,000 years ago.

The second set of traits belonging to modern humans

"It is not yet clear whether the archaic DNA many of us carry is tied. to any visible traits." include the regional or 'racial' features that differentiate human populations, such as facial shape, form of the eyelids, type of hair, skin pigmentation and physique. I have argued that these regional features were added as people spread in small numbers after the shared modern human template had evolved in Africa. The processes involved were natural selection (Charles Darwin's favoured evolutionary mechanism in his 1859 On the Origin of Species), different sexual or cultural preferences (emphasized in Darwin's 1871 volume The Descent of Man), a founder effect as remote regions were colonized by small pioneer groups, and drift, as newly separated populations diverged through random processes.

That dispersal event potentially brought early modern humans into the realms of other hominin populations living outside Africa, including the Neanderthals in western Eurasia, and Homo floresiensis and the ancient species Homo erectus in Indonesia. The first DNA to be successfully recovered from Neanderthal fossils seemed to support the view

\section{A WINDING PATH}

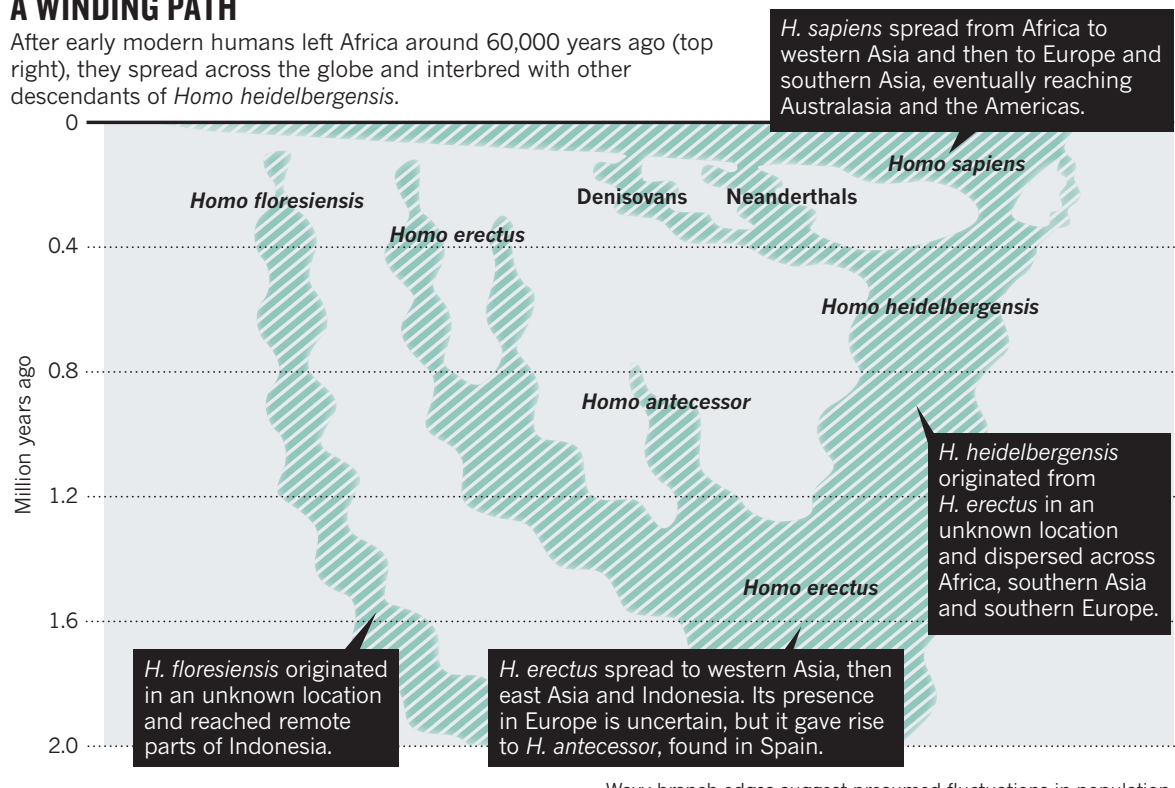

that the Neanderthals represented a lineage and species that was separate from all recent humans. However, increasingly complete genomic reconstructions from Neanderthal fossils ${ }^{4}$ and from a newly characterized group called Denisovans - so far known only from a single cave in southern Siberia ${ }^{5}$ - have shown these hominins to be related populations that descended from the earlier species Homo heidelbergensis, which also gave rise to H. sapiens (see 'A winding path').

Comparative genomic studies have revealed elements of DNA that are unique to each of the three groups (recent humans, Neanderthals and Denisovans), some of which could be expressed in the phenotype, and that may be related to such things as the physiology of the brain, skin, skeleton and even sperm ${ }^{4,5}$. But the biggest surprise for many researchers was the evidence from whole genome scans that modern humans living outside Africa each carry about $2.5 \%$ of their DNA from Neanderthals; furthermore, people living today in Australia and New Guinea (Australasians) carry about 5\% of Denisovan DNA ${ }^{4,5}$ (see 'Patchwork planet').

The most likely explanation is interbreeding, such as when modern humans emerged from Africa into Eurasia about 60,000 years ago and met Neanderthals, and when the ancestors of Australasians met some Denisovans. Scientists are continuing to study these archaic genomes in detail, and are finding clear variation within and between nonAfrican people in the amount and kind of archaic DNA that survives in their genomes today. In short, people living outside Africa carry different quantities, and distinct remnants, of archaic DNA from those interbreeding events. Some African populations may also contain genes from ancient groups as a result of interbreeding, as shown by recent DNA evidence ${ }^{6}$ and 15,000-year-old fossils from Central and West Africa, which have some ancestral traits such as a longer, lower braincase . $^{3}$.

This evidence of interbreeding between groups that palaeontologists call separate species raises two crucial questions. First, given that most of us learned at school that species don't interbreed, should we change the definition we use for a species? Or should we remove the taxonomic separations erected purely from the morphology of fossils, and sink $H$. heidelbergensis, Neanderthals and Denisovans into H. sapiens? And second, how does the evidence of interbreeding affect our concept of modern humans, when the genomes of people today apparently contain differing levels of archaic genes?

\section{LAID TO REST}

In my view, the evidence that $H$. sapiens interbred with archaic humans does not yet require a merging of these close relatives into a single expanded concept of $H$. sapiens. 


\section{PATCHWORK PLANET}

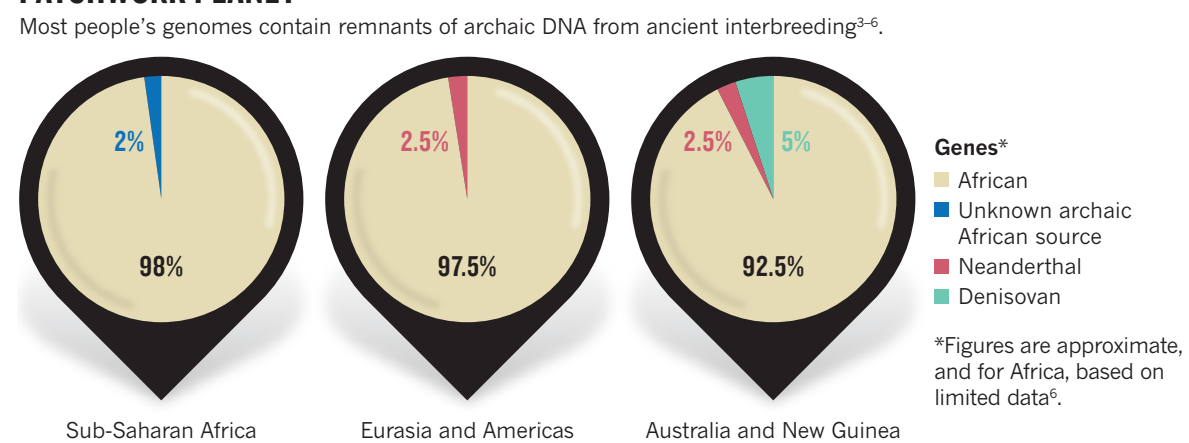

Doing so would produce a species that had a range of morphological variation several times that found in humans today, or in other existing primate species. These human lineages were distinct enough to build up well-differentiated genotypes and phenotypes (although we know little of the Denisovan phenotype so far) - even the inner ear bones of a Neanderthal are readily distinguishable from those of a modern human. Furthermore, many closely related species of primates undergo limited interbreeding, including among our close ape and monkey relatives ${ }^{7}$. So, for pragmatic reasons, I would retain these species categories while recognizing that this does not imply complete reproductive isolation ${ }^{3}$.

It is not yet clear whether the archaic DNA many of us carry is tied to any visible traits. Are some of the regional physical differences that I argue have largely evolved in the past 60,000 years within dispersing modern humans instead the result of Neanderthal or Denisovan genes? Europeans do not seem to have inherited lighter pigmentation or cold adaptation from their Neanderthal predecessors, but what about their large noses or immune systems ${ }^{8}$ ? What about the distinctive teeth and malarial resistance of some Australasians - could these be signs of a Denisovan heritage?

More controversially, some of the known differences in coding DNA between Neanderthals and recent humans are associated with brain development and function ${ }^{4}$. Although the archaeological record of Africa suggests that it was the centre of origin for many innovations in modern human behaviour such as complex tools, symbolism and marine exploitation, some have argued that it was only on leaving Africa that modern humans ratcheted up their cognitive skills in response to the environmental challenges of Eurasia ${ }^{9}$. Now, instead, researchers may start to examine the possible phenotypic expression of Neanderthal, Denisovan or African archaic genes for cognition and intelligence.

Terms such as 'archaic' and 'primitive' may be considered objective when used by palaeontologists, but they can be pejorative in common parlance. If researchers want to continue the progress recently made in studying the origins of modern human variation, they will need to think long and hard about their aims, and the lexicon they use.

One thing should be reiterated: all living humans are members of the extant species $H$. sapiens and, by definition, all must equally be modern humans. The majority of our genes (>90\%) derives from our common African heritage, and this should take precedence over the minor amount of DNA that is different - however and whenever it was acquired. It is important that we examine all the factors that lie behind our evolution, including the possible effects of interbreeding on the physiology of modern humans, but we will have learnt nothing in the past 50 years if we let small segments of distinct DNA govern the way we regard regional variation today. SEE NEWS FEATURE P.23

Chris Stringer is research leader in human origins in the Department of Earth Sciences at the Natural History Museum, London SW7 5BD, UK.

e-mail:c.stringer@nhm.ac.uk

1. Day, M. H. \& Stringer, C. B. L'Anthropologie 95, 573-594 (1991).

2. Wolpoff, M. H. Describing Anatomically Modern Homo sapiens: A Distinction without a Definable Difference. In Fossil Man: New Facts, New Ideas. Papers in Honour of Jan Jelínek's Life Anniversary (eds Novotný V.V. and Mizerová, A.) Anthropos (Brno) 23, 41-53 (1986).

3. Stringer, C. Lone Survivors: How We Came to be the Only Humans on Earth (Times Books, 2012).

4. Green, R. E. et al. Science 328, 710-722 (2010).

5. Reich, D. et al. Nature 468, 1053-1060 (2010).

6. Hammer, M., Woerner, A., Mendez, F., Watkins, J. \& Wall, J. Proc. Natl Acad. Sci. USA 108, 15123-15128 (2011)

7. Jolly C. J. Evol. Anthropol. 18, 275-281 (2009).

8. Abi-Rached, L. et al. Science 334, 89-94 (2011).

9. Kohn, M. The Race Gallery: The Return of Racial Science (Jonathan Cape, 1995).

\section{CORRECTION}

The article 'A plan for mental illness' (Nature 483, 269; 2012) omitted to provide the full list of authors and the conflicting financial interests declared by some of them. This has been rectified online at go.nature.com/t1ihrn. 